\title{
Role of vandetanib in the management of medullary thyroid cancer
}

\author{
This article was published in the following Dove Press journal: \\ Biologics:Targets and Therapy \\ 7 March 2012 \\ Number of times this article has been viewed
}

\author{
Maryse Brassard ${ }^{*}$ \\ Geneviève Rondeau ${ }^{2 *}$ \\ 'Endocrinology Service, Department \\ of Medicine, Centre Hospitalier \\ Universitaire Affilié (CHA), Laval \\ University, Quebec, Canada; \\ ${ }^{2}$ Endocrinology Service, Department \\ of Medicine, Centre Hospitalier de \\ I'Université de Montréal (CHUM), \\ University of Montreal, Montreal, \\ Canada \\ *Both authors contributed equally \\ to this article
}

\begin{abstract}
Traditionally available treatments, like cytotoxic chemotherapy and external-beam radiation therapy, are limited and essentially ineffective for metastatic medullary thyroid carcinoma (MTC). In the last decade, small-molecule tyrosine kinase inhibitors (TKI) have been introduced in the field of thyroid cancer, after having been shown effective in a wide variety of other tumors. This review focuses on vandetanib (ZD6474, Zactima ${ }^{\mathrm{TM}}$; AstraZeneca) and its role in the treatment of MTC. Vandetanib is an oral TKI that targets VEGF receptors 2 and 3, RET, and at higher concentrations, the epidermal growth factor (EGF) receptor. This drug has been tested in two important phase II studies which demonstrated that both the 100 and $300 \mathrm{mg}$ /day dosage of vandetanib have antitumor activity on advanced MTC. A phase III trial (ZETA trial) evaluating vandetanib in 331 patients with locally advanced or metastatic MTC showed a significant prolongation of PFS for patients receiving vandetanib compared with placebo. Toxicity surveillance in all studies reported high rates of adverse effects with diarrhea, rash, fatigue and nausea being the most commonly experienced by patients. Vandetanib is currently approved in the United States for unresectable locally advanced or metastatic MTC and has become a new standard of care in this rare and indolent pathology.
\end{abstract}

Keywords: vandetanib, medullary thyroid cancer, RET mutation, VEFGR

\section{Introduction}

Medullary thyroid cancer (MTC) is a neuroendocrine tumor originating from parafollicular cells of the thyroid and which accounts for fewer than $10 \%$ of all diagnosed thyroid cancers. Characterized as a rare and indolent malignancy, it is nevertheless overrepresented among thyroid cancer-related deaths. Hereditary forms of this cancer account for $25 \%$ of cases, and include familial MTC (FMTC) and multiple endocrine neoplasia syndromes (MEN2A and MEN2B), but its more common presentation remains in its sporadic form ( $75 \%$ of cases). ${ }^{1}$ If diagnosed and treated at an early stage when the tumor is confined to the thyroid, MTC usually has a favorable prognosis, with a 10 -year survival rate of $70 \%-80 \% .{ }^{2}$ Conversely, locally advanced cervical disease and extra-cervical metastasis are incurable. Its distant metastatic form has the least favorable prognosis, a survival rate of $40 \%$ at 10 years, and it is the main cause of death in patients with MTC. ${ }^{2}$ Traditionally available treatments, like cytotoxic chemotherapy and external-beam radiation therapy, are limited and essentially ineffective for metastatic MTC. In the last decade, small-molecule tyrosine kinase inhibitors (TKI), which target multiple kinases, have been introduced in the field of thyroid cancer, after having been shown effective in a wide variety of other tumors. This review focuses on vandetanib (ZD6474, Zactima ${ }^{\mathrm{TM}}$; AstraZeneca, Mississauga, ON)
Correspondence: Maryse Brassard

2705 Boulevard Laurier,

Quebec (Que), GIV 4G2 Canada

$\mathrm{Tel}+\mathrm{I} 4186542169$

Fax + I 4186542792

Email maryse.brassard@usherbrooke.ca 
and on targeting rearranged during transfection (RET) receptor tyrosine kinase activation in MTC.

\section{RET proto-oncogene}

As is well known, MTC is associated with the RET protooncogene on chromosome 10q11.2. The RET receptor protein is part of a large family of receptors, receptor tyrosine kinases (RTK), characterized for their role in cell growth, differentiation, survival, and programmed cell death. ${ }^{3}$ In response to binding of extracellular ligands, RTKs form homodimers or heterodimers. After dimerization, autophosphorylation followed by intracellular signal transduction occur through effectors that recognize and interact with the phosphorylated form of $\mathrm{RTK}^{4}$ (Figure 1). This ligand-receptor interaction is very specific, while the downstream signaling pathways may be shared by different receptors. ${ }^{4}$

RET was one of the first RTKs to be implicated in tumorigenesis. Germline mutations in the RET protooncogene are responsible for hereditary MTC while up to half of the sporadic forms of MTC harbor somatic RET mutations. ${ }^{5,6}$ This provides a strong rationale for targeting RET in selective cancer therapy. Moreover, RET gene mutations have a high correlation between genotype and phenotype, with a clear link between the identified mutation and tumor behavior, thus affecting aggressiveness of treatment and follow-up. ${ }^{3}$

\section{Vascular endothelial growth factor receptor pathway}

The vascular endothelial growth factor receptor (VEGFR) pathway is also important in the pathogenesis of MTC. ${ }^{7}$ There are three transmembrane receptors that mediate the angiogenic and lymphogenic effects of VEGF: VEGFR-1, VEGFR-2, and VEGFR-3. VEGFR-2 is thought to be the one implicated in tumor growth and metastasis, as it plays a role in endothelial cell proliferation, migration, and survival as well as induction of neovascularization (Figure 2). Tumor cells secrete VEGF proteins (VEGF-A, B, C, and D) that act as ligands for the VEGF receptors, which initiate a cascade of different pathways including PLC $\gamma$-PKC-Raf-MEK-MAPK and $\mathrm{PI} 3 \mathrm{~K}-\mathrm{Akt}$, towards promoting angiogenesis. ${ }^{8}$ There is a twofold overexpression of VEGF and VEGFR-2 in MTC when compared to normal thyroid tissue. ${ }^{7}$ Overexpression of VEGFR-2 in MTC correlates with metastasis. ${ }^{9}$

\section{Other TK receptors implicated in MTC tumorigenesis}

Epidermal growth factor receptor (EGFR) is a TK receptor that acts downstream through activation of several cascades, including MAPK and Pi3K pathways. Although EGFR mutations are rare, a study of 153 primary and metastatic MTC samples showed that EGFR expression was more

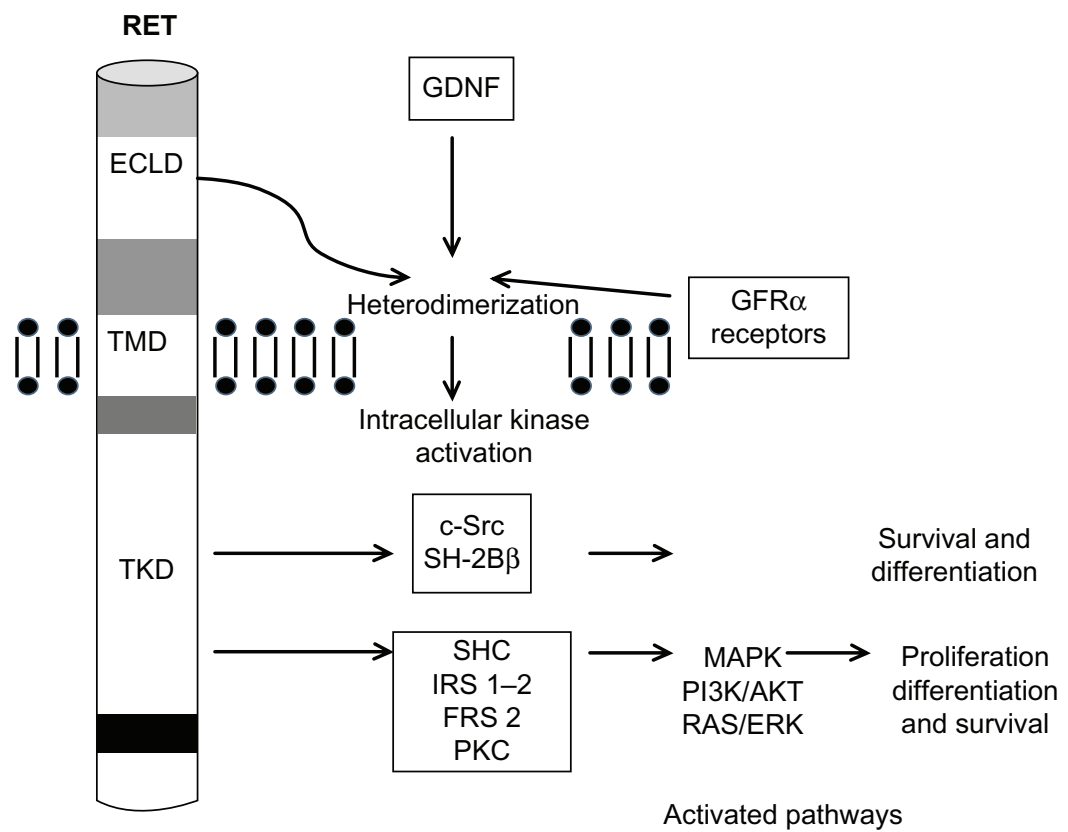

Figure I Interaction of ligand with RET and cell-signaling pathways.

Abbreviations: AKT, serine/threonine protein kinase; ECLD, extracellular ligand domain; FRS 2, fibroblast growth factor receptor substrate 2; GDNF, glial cell line-derived neurotrophic factor; GFR $\alpha$, GDNF family receptor; IRS I-2, insulin receptor substrate I and 2; MAPK, mitogen-activated protein kinase; PI3K, phosphoinositide 3-kinase; RAS/ERK, extracellular signal-regulated kinase; PKC, protein kinase C; RET, rearranged during transcription; SHC, Src homology and collagen; TKD, tyrosine kinase domain; TMD, transmembrane domain. 


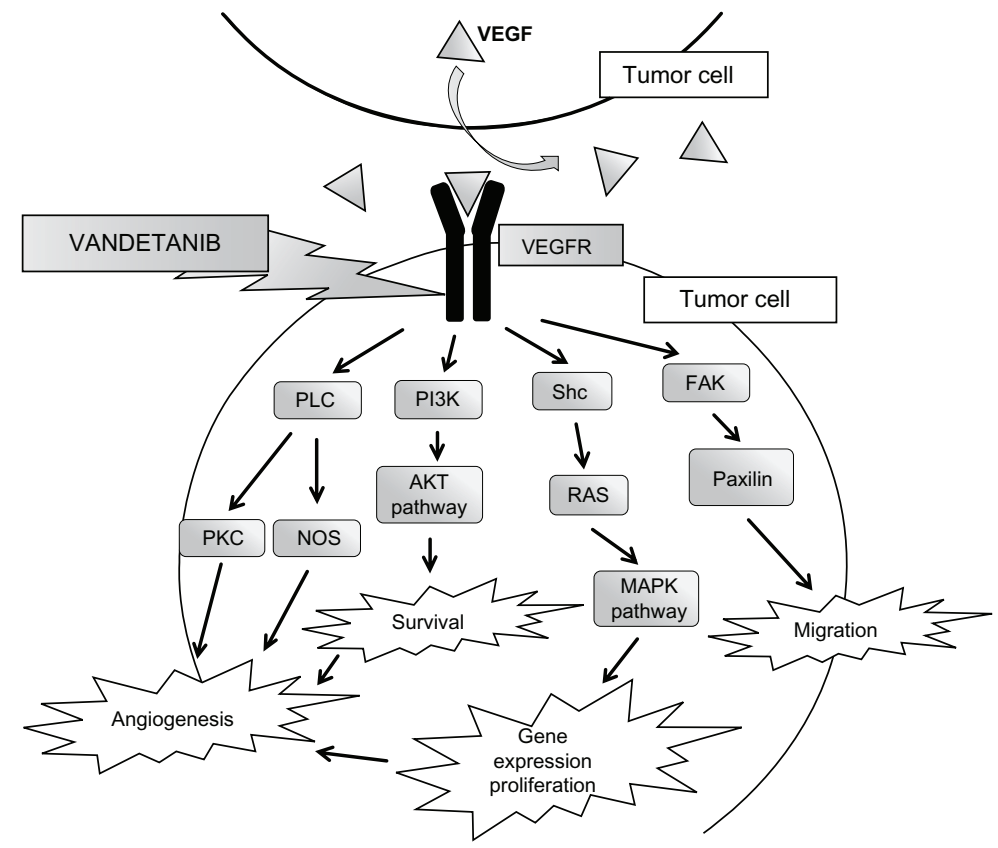

Figure 2 VEGFR pathways within the tumor cell.

Abbreviations: AKT, serine/threonine protein kinase; FAK, focal adhesion kinase-I; MAPK, mitogen-activated protein kinase; NOS, nitric oxide synthase; PI3K, phosphoinositide 3-kinase; PLC, phospholipase; PKC, protein kinase; Shc, proteins containing Src homology-2 domains; RAS, rat sarcoma; VEGF, vascular endothelial growth factor; VEGFR, VEGF receptor.

important in metastasis than in the primary tumor site of MTC. ${ }^{9}$

The $c$-met $(M E T)$ proto-oncogene also plays a role in tumor cell proliferation. It codes for the TK receptor of the hepatocyte growth factor. ${ }^{8}$ Its overexpression has been reported in mutifocal MTC. ${ }^{10}$

\section{Vandetanib as a targeted therapy}

A few different pathways are activated in MTC cells. No selective RET inhibitor is currently available, but a few multikinase inhibitors have significant activity against RET. Small-molecule tyrosine kinase inhibitors (TKI) typically affect multiple signaling pathways. Vandetanib is a 4-anilinoquinazoline, available as an oral TKI that targets VEGF receptors 2 and 3, RET, and at higher concentrations, EGFR. ${ }^{11}$ It docks to the adenosine triphosphate (ATP)binding pocket of the RET kinase which confers an inhibiting effect. ${ }^{12}$ It was initially developed as a second-generation EGF receptor TKI, as its more potent inhibitory effects against VEGF receptor were demonstrated later on. ${ }^{3}$ In thyroid cancer cell lines, it was shown to be effective in inhibiting RET/PTC1 and RET/PTC3 mutations in some PTCs and M918T RET mutations in MEN2B and some sporadic MTCs. RET mutations in certain inherited forms of MTC, as in codon 804 and 806, seem to confer resistance to vandetanib. ${ }^{13,14}$

\section{Preclinical studies}

Vandetanib was shown to be effective in in vitro studies by inhibiting VEGF- and EGF-stimulated cell growth, with activities $\left(50 \%\right.$ inhibitory concentration, $\left.\left[\mathrm{IC}_{50}\right]\right)$ on tyrosine kinases of $1600 \mathrm{nM}$ for VEGFR1, $40 \mathrm{nM}$ for VEGFR2, $108 \mathrm{nM}$ for VEGFR3, and $500 \mathrm{nM}$ for EGFR. ${ }^{15}$ It also inhibits RET proto-oncogenic kinase $\left(\mathrm{IC}_{50}, 100 \mathrm{nM}\right)$ and RET-dependent thyroid tumor cell proliferation in vitro. ${ }^{16}$

In MTC cells bearing a $\mathrm{RET}^{\mathrm{C} 634 \mathrm{~W}}$-activating mutation, vandetanib (200 $\mathrm{nM})$ has a significant antiproliferative effect as soon as 3 days after treatment introduction. After 6 days, vandetanib (250 $\mathrm{nM})$ reduces calcitonin secretion (1.9-fold) and calcitonin mRNA expression (twofold). In athymic mice bearing MTC tumors, vandetanib (50 mg/kg/day) induced a 14.5-fold reduction of tumor volume after 45 days of treatment. Treated xenografts displayed a significant decrease in the number of tumor cells, mitotic index (Ki67), and tumor angiogenesis (CD34 staining). ${ }^{17}$ Another group showed that upon RET inhibition applied on $R E T^{C 634 W}$ and $R E T^{M 918 T}$ mutated cell lines, adoptive stimulation of EGFR partially rescues proliferation, MAPK signaling, and expression of cell-cycle-related genes. ${ }^{18}$ This may suggest that simultaneous inhibition of RET and EGFR by vandetanib might overcome the risk of MTC cells escaping from RET blockade through compensatory over-activation of EGFR. 
The administration of vandetanib at different doses (12.5, 25,50 , or $100 \mathrm{mg} / \mathrm{kg} /$ day) produced a significant, dosedependent inhibition of tumor growth ${ }^{15}$ and a significant reduction in tumor microvessel density ${ }^{19-22}$ in a very wide range of human tumor xenograft models, including breast, lung, prostate, colon, kidney, ovary, and others. Vandetanib also seems to be effective against anaplastic thyroid carcinoma (ATC), as it significantly inhibits tumor growth of ATC cell lines in vivo by more than $65 \%$ when compared to control.

A dynamic contrast-enhanced magnetic resonance imaging (MRI) analysis disclosed a dose-dependent reduction in contrast agent uptake by tumors as soon as 24 hours after starting vandetanib treatment in human xenograft models of prostate ${ }^{23}$ and colon ${ }^{24}$ cancer. Furthermore, it seems promising that metabolic imaging with ${ }^{18} \mathrm{~F}$-fluorodeoxyglucose positron emission tomography (FDG-PET) was recently shown to assess changes in tumoral glucose metabolism profile as early as 3 days after initiation of vandetanib in human MTCbearing mice. The authors hypothesize that FDG-PET may be useful for identifying patients who respond to vandetanib early on in the course of treatment. ${ }^{25}$

A comparison was performed on the effect of four TKI (vandetanib, axitinib, sunitinib, and XL184) on cell proliferation, RET expression, and autophosphorylation, as well as ERK activation in cell lines expressing either a MEN2A (MTC-TT), a MEN2B (MZ-CRC-1) mutation, or a RET/ $P T C$ (TPC-1) rearrangement. The authors found that there was indeed specificity for different RET mutations, with vandetanib being the most potent inhibitor in MEN2B, and XL184 the most effective in MEN2A and PTC in vitro. No TKI was superior for all cell lines tested, indicating that mutation-specific therapies could be beneficial in treating MTC and PTC. ${ }^{26}$

\section{Phase I clinical studies}

In order to determine its safety, tolerability, and pharmacokinetics, three phase I single-agent clinical studies involving vandetanib in patients with solid malignant tumors refractory to standard therapy were published. The first trial included 77 American and Australian patients with various tumors, with colorectal cancer being the most common. ${ }^{27}$ All but one patient experienced at least one adverse event (AE), with diarrhea, hypertension, and rash being the most common dose-limiting toxicities (DLT). Seven patients experienced asymptomatic corrected QT (QTc) prolongation. The incidence of most adverse events appeared to be dose-dependent. Pharmacokinetic analysis revealed that a $t_{1 / 2}$ of $\sim 120$ hours, and a minimum of 28 days continuous oral dosing with vandetanib was required to achieve steady-state plasma concentrations. These data confirmed that vandetanib was suitable for once-daily oral administration and among the various doses ranging from 50 to $600 \mathrm{mg} /$ day, $300 \mathrm{mg} /$ day was recommended for further phase II studies. In this study, no patient achieved a complete or partial tumor response as evaluated by Response Evaluation Criteria in Solid Tumors (RECIST) $1.0 .^{28}$

The second phase I study involved 18 Japanese patients with solid tumors, nine of which were non-small-cell lung cancer (NSCLC). ${ }^{29}$ The most common drug-related AEs were rash, asymptomatic prolongation of QTc interval, diarrhea, and proteinuria. Mean arterial blood pressure increased in most patients after multiple doses of ZD6474. QTc prolongation necessitated dose interruption in seven out of 12 patients, six of whom were able to resume vandetanib treatment at a reduced dosage. QTc prolongation was reported at all dosages studied, with no clear evidence of dose-dependency. No grade 4 drug-related AE was observed. Seven patients experienced grade 3 drug-related AEs, most commonly hypertension. Pharmacokinetics findings of the first phase I study were confirmed, and again the dose of $300 \mathrm{mg} /$ day was deemed appropriate because of hypertension and elevated alanine aminotransferase (ALT) levels being reported as DLTs in the 400-mg group. Objective tumor response was observed in four out of nine patients with NSCLC at doses of either 200 or $300 \mathrm{mg}$.

A third study included 36 Chinese patients with solid tumors, most being lung cancers, and among them, three patients had MTC. ${ }^{30}$ The most common drug-related AEs were rash and diarrhea. No QTc prolongation was observed, and most importantly, patients were receiving no more than $300 \mathrm{mg} /$ day of vandetanib. Of note, only one patient showed a partial tumor response, and this patient had MTC.

\section{Phase II clinical studies}

The first available phase II study using vandetanib in patients with unresectable MTC was performed by a group of investigators based in the United States and France. ${ }^{31}$ Thirty patients with locally advanced or metastatic MTC were assigned to vandetanib $300 \mathrm{mg} /$ day in this open-label, single-arm trial conducted at seven centers. All patients had a germline RET mutation, most with MEN2A (33\% of the cohort). Among other key inclusion criteria was the presence of at least one measurable lesion according to 
RECIST guidelines. ${ }^{32}$ The primary end-point of the study was objective response rate, and additional assessments included duration of response, disease control, progression-free survival (PFS), safety and tolerability, and changes in serum levels of calcitonin and carcinoembryonic antigen (CEA).

At study entry, 29 patients had distant metastases, including sites at liver (80\%), lymph nodes (70\%), and lung $(63 \%)$. Twenty percent of patients (ie, six of 30 patients) experienced a confirmed partial response (median duration of response at data cutoff, 10.2 months). An additional 53\% of patients (ie, 16 of 30 patients) experienced stable disease at $\geq 24$ weeks, which yielded a disease control rate of $73 \%$ (ie, 22 of 30 patients). In 24 patients, serum calcitonin levels showed a $50 \%$ or greater decrease from baseline that was maintained for at least 4 weeks; 16 patients showed a similar reduction in serum CEA levels. The most common adverse events were diarrhea (70\%), rash (67\%), fatigue (63\%), and nausea $(63 \%)$.

The second phase II trial, performed by a group of investigators from Australia and the United States, had the same eligibility criteria. ${ }^{33}$ Included in the study were 19 patients with unresectable and measurable MTC, all with RET positive status. It was an open-label, single arm trial using a lower dose of vandetanib of $100 \mathrm{mg} /$ day. The primary objective of this study was also to assess the objective response rate with vandetanib according to RECIST, ${ }^{32}$ and the secondary objectives were identical to the first phase II trial by Wells et al. ${ }^{31}$

Eighteen patients had metastatic disease in liver (84\%), bones and lungs (42\% for each), and most had MEN2A (47\%). Confirmed objective partial responses were observed in three patients, yielding an objective response rate of 16\% (95\% confidence interval [CI]: 3.4-39.6). Stable disease lasting 24 weeks or longer was reported in a further 10 patients (53\%); disease control rate was therefore $68 \%$ (95\% CI: 43.4-87.4). Serum levels of calcitonin and CEA showed a sustained $50 \%$ or greater decrease from baseline in $16 \%$ (three of 19) and 5\% (one of 19) of patients, respectively. There was no apparent association between RET germline mutation and clinical outcome in this study. Adverse events were predominantly of grade 1 or 2 and consistent with other vandetanib studies, namely diarrhea (47\%), fatigue (42\%), and rash (26\%). The authors concluded that taken together, the two phase II studies demonstrate that both the 100 and $300 \mathrm{mg} /$ day dosage of vandetanib have antitumor activity on advanced MTC. No direct comparison of the efficacy at each dose level has been conducted; therefore no conclusion could be made with regard to the relative efficacy of the 100 and $300 \mathrm{mg} /$ day doses in MTC.

\section{Phase III clinical study}

According to these encouraging results, a group of investigators from the United States, France, Italy, and the United Kingdom performed an international randomized, placebo-controlled, double-blind, phase III study (ZETA) to evaluate vandetanib in patients with locally advanced or metastatic MTC. ${ }^{34}$ Adult patients were eligible if they had measurable, unresectable locally advanced or metastatic, hereditary or sporadic MTC. Another key inclusion criterion was a serum calcitonin level over $500 \mathrm{pg} / \mathrm{mL}$. It is noteworthy that progression of disease at study entry was not mandatory. Patients were randomly assigned in a 2:1 ratio to receive oral vandetanib at a starting dose of $300 \mathrm{mg} /$ day or placebo until disease progression. Upon objective disease progression, patients discontinued the study drug, were unblinded, and could enter postprogression, open-label treatment with vandetanib. The primary objective was to determine whether vandetanib prolonged PFS, and secondary assessments included objective response rate, disease control rate at 24 weeks, duration of response, overall survival, biochemical response (decrease in calcitonin and CEA serum levels), and time to worsening of pain.

Three hundred thirty-one patients recruited from 23 countries were randomly assigned to either vandetanib (231) or placebo (100). The majority of patients presented with sporadic disease, and almost all had metastatic disease at study entry. The most common metastatic sites were liver, lymph nodes, and lungs. At data cut-off, the median duration of follow-up was 24 months, and 139 patients were continuing blinded treatment: $111(48 \%)$ were randomly assigned to vandetanib and $28(28 \%)$ to placebo. Significant prolongation of PFS was observed for patients receiving vandetanib compared with placebo (hazard ratio [HR], 0.46; 95\% CI: $0.31-0.69 ; P<0.001)$. The median PFS was 19.3 months in the placebo group and, although the median had not yet been reached for the vandetanib group, a statistical model indicated a predicted median PFS of 30.5 months. Vandetanib also showed significant benefits compared to placebo in the secondary efficacy end-points of objective response rate, disease control rate, and calcitonin and CEA biochemical response rates. As expected, overall survival data were immature at data cut-off. Interestingly, in patients with sporadic MTC, a subgroup analysis of PFS by M918T somatic mutation suggested that the patients who were 
mutation-positive had a higher response rate to vandetanib compared with M918T mutation-negative patients. Adverse events such as diarrhea, rash, nausea, and hypertension occurred in more than $30 \%$ of patients receiving vandetanib. Twelve percent of patients on vandetanib discontinued treatment during the randomized phase because of an adverse event (versus 3\% in patients receiving placebo). This rate of treatment discontinuation because of toxicity was considered low by the authors, despite a median duration of treatment of approximately 1 year and 9 months. Nineteen patients (8\%) developed protocol-defined QTc prolongation, but there were no reports of torsade de pointes. Five patients on the vandetanib arm experienced adverse events leading to death during the randomized phase; these were single instances of aspiration pneumonia, respiratory arrest, respiratory failure, staphylococcal sepsis, and arrhythmia and acute cardiac failure in one patient.

\section{Toxicity of vandetanib}

As reported above in clinical studies, the most common toxicities of vandetanib in MTC are diarrhea, fatigue, rash, and nausea. As most patients will develop an adverse event on the recommended dose of $300 \mathrm{mg}$ /day (see Table 1), the drug prescriber should be comfortable with treatment and follow-up of these toxicities. ${ }^{35}$ The majority of adverse events reported were manageable according to standard clinical practice alone or in combination with vandetanib dose reductions, which allowed patients to continue receiving vandetanib treatment for extended periods of time.

Unusual adverse events have been reported. A case of reversible cerebral vasoconstriction syndrome has been documented in a patient with metastatic MTC, presenting as a severe acute headache and nausea 3 days after starting vandetanib. ${ }^{36}$ The cerebral arteriography showed a characteristic string-bead pattern of alternating areas of arterial stenosis and dilation. After vandetanib was stopped, the patient rapidly recovered from his symptoms and an angiography performed 3 months later documented complete resolution of arterial constriction.

Another miscellaneous complication of therapy with vandetanib is the development of corneal verticillata, also known as vortex keratopathy, reported in a patient treated for anaplastic astrocytoma and consisting of subepithelial whorls that may lead to ocular surface irritation and corneal erosions. ${ }^{37}$ The authors state that these corneal changes may be related to the anti-EGFR action of vandetanib and are implicated in the pathogenic mechanisms of ocular surface diseases involving rapid epithelial turnover.

Finally, one of the authors (MB) assessed the endocrine effects of vandetanib in 39 patients with progressive medullary or differentiated thyroid cancer included in two randomized placebo-controlled trials using vandetanib $300 \mathrm{mg} / \mathrm{day} .{ }^{38}$ On vandetanib treatment, calcium and vitamin $\mathrm{D}$ mean replacement doses were increased; calcium level remained unchanged, but serum $25(\mathrm{OH})$ vitamin D level decreased, and serum PTH and 1,25(OH) vitamin D levels increased, suggesting a decreased intestinal absorption of vitamin D or lack of sun exposure as a result of photosensitization induced by vandetanib. Levothyroxine had to be increased by $50 \mu \mathrm{g} /$ day to maintain serum thyroid-stimulating hormone within the normal range, probably by increased type 3 deiodinase activity as described with sorafenib. ${ }^{39}$ In male patients, total testosterone, bioavailable testosterone, and sex hormone-binding globulin levels were increased for unknown reasons. Serum inhibin-B decreased and stimulated follicle-stimulating hormone increased coherently, suggesting a Sertoli cells insufficiency. Cortisol level increased as well as adrenocorticotropic and cortisol-binding globulin levels, but free urinary cortisol levels remained in the normal range. None of these changes were observed in patients randomized to the placebo arm.

Table I Major adverse events reported in $20 \%$ or more patients on vandetanib $300 \mathrm{mg} /$ day versus placebo in MTC

\begin{tabular}{|c|c|c|c|c|c|c|}
\hline & \multirow{2}{*}{\multicolumn{2}{|c|}{$\begin{array}{l}\text { Wells et } \mathrm{al}^{31} \\
\text { Vandetanib } 300 \mathrm{mg} / \text { day } \\
\mathrm{n}=30(\%)\end{array}$}} & \multicolumn{4}{|c|}{ Wells et $\mathrm{al}^{34}$} \\
\hline & & & \multicolumn{2}{|c|}{$\begin{array}{l}\text { Vandetanib } 300 \mathrm{mg} / \mathrm{day} \\
\mathrm{n}=23 \mathrm{I}(\%)\end{array}$} & \multicolumn{2}{|l|}{$\begin{array}{l}\text { Placebo } \\
n=100(\%)\end{array}$} \\
\hline & Grade I-2 & Grade 3+ & Grade I-2 & Grade 3+ & Grade I-2 & Grade 3+ \\
\hline Diarrhea & 60 & 10 & 45 & II & 4 & 2 \\
\hline Fatigue & 57 & 7 & 18 & 6 & 22 & 1 \\
\hline Rash & 63 & 3 & 41 & 4 & 10 & I \\
\hline Nausea & 63 & 10 & 33 & NR & 16 & NR \\
\hline Hypertension & 23 & 10 & 23 & 9 & 5 & 0 \\
\hline ECG QTc prolongation & NR & 20 & 6 & 8 & 0 & I \\
\hline Decreased appetite & 40 & 3 & 17 & 4 & 12 & 0 \\
\hline
\end{tabular}

Abbreviations: ECG, electrocardiographic; MTC, medullary thyroid carcinoma; NR, data not reported; QTc, corrected QT. 


\section{Role of vandetanib in the treatment of MTC}

Vandetanib was approved by the US Food and Drug Administration (FDA) in April 2011. ${ }^{40}$ It is still under review in Europe and Canada. This drug is approved for patients with advanced locoregional or metastatic MTC that is unresectable, progressive and/or symptomatic. Patients experiencing a rapid calcitonin doubling-time, but yet with microscopic disease, are not part of the approved indications of the drug since benefits in that specific population are not known. Vandetanib has now become the new standard of care for patients with unresectable or metastatic MTC in the United States. Its use is however strictly regulated due to its potential cardiac toxicity, as mentioned above. These potential cardiac effects are addressed by the FDA in a black box warning. Monitoring with serial EKGs and serum potassium, calcium and magnesium levels (at baseline, $2-4$ weeks, and 8-12 weeks after treatment initiation and then every 3 months) is recommended.$^{41}$ As with other TKI, vandetanib's high cost may limit its availability to all patients.

\section{Conclusion}

In summary, with its development as a targeted agent and the encouraging phase II and III trials results, vandetanib is recognized as an effective therapy in advanced MTC. Further studies of this drug in combination or in sequence with other TKIs are awaited as supplementary uses of vandetanib may emerge.

\section{Disclosures}

GR has been a consultant for AstraZeneca. MB has received honoraria from Abbott and has been a consultant for AstraZeneca.

\section{References}

1. Kouvaraki MA, Shapiro SE, Perrier ND, et al. RET proto-oncogene: a review and update of genotype-phenotype correlations in hereditary medullary thyroid cancer and associated endocrine tumors. Thyroid. 2005;15(6):531-544.

2. Roman S, Lin R, Sosa JA. Prognosis of medullary thyroid carcinoma: demographic, clinical, and pathologic predictors of survival in 1252 cases. Cancer. 2006;107(9):2134-2142.

3. Phay JE, Shah MH. Targeting RET receptor tyrosine kinase activation in cancer. Clin Cancer Res. 2010;16(24):5936-5941.

4. Eng C. RET proto-oncogene in the development of human cancer. J Clin Oncol. 1999;17(1):380-393.

5. Hofstra RM, Landsvater RM, Ceccherini I, et al. A mutation in the RET proto-oncogene associated with multiple endocrine neoplasia type $2 \mathrm{~B}$ and sporadic medullary thyroid carcinoma. Nature. 1994;367(6461): 375-376.

6. Mulligan LM, Kwok JB, Healey CS, et al. Germ-line mutations of the RET proto-oncogene in multiple endocrine neoplasia type 2A. Nature. 1993;363(6428):458-460.
7. Capp C, Wajner SM, Siqueira DR, Brasil BA, Meurer L, Maia AL. Increased expression of vascular endothelial growth factor and its receptors, VEGFR-1 and VEGFR-2, in medullary thyroid carcinoma. Thyroid. 2010;20(8):863-871.

8. Gómez K, Varghese J, Jimenez C. Medullary thyroid carcinoma: molecular signaling pathways and emerging therapies. J Thyroid Res. 2011;2011:815826.

9. Rodriguez-Antona C, Pallares J, Montero-Conde C, et al. Overexpression and activation of EGFR and VEGFR2 in medullary thyroid carcinomas is related to metastasis. Endocr Relat Cancer. 2010;17(1):7-16.

10. Papotti M, Olivero M, Volante M, et al. Expression of hepatocyte growth factor (HGF) and its receptor (MET) in medullary carcinoma of the thyroid. Endocr Pathol. 2000;11(1):19-30.

11. Sherman SI. Targeted therapies for thyroid tumors. Mod Pathol. 2011; 24(Suppl 2):S44-S52.

12. Knowles PP, Murray-Rust J, Kjaer S, et al. Structure and chemical inhibition of the RET tyrosine kinase domain. J Biol Chem. 2006; 281(44):33577-33587.

13. Carlomagno F, Guida T, Anaganti S, et al. Disease associated mutations at valine 804 in the RET receptor tyrosine kinase confer resistance to selective kinase inhibitors. Oncogene. 2004;23(36): 6056-6063.

14. Carlomagno F, Guida T, Anaganti S, et al. Identification of tyrosine 806 as a molecular determinant of RET kinase sensitivity to ZD6474. Endocr Relat Cancer. 2009;16(1):233-241.

15. Wedge SR, Ogilvie DJ, Dukes M, et al. ZD6474 inhibits vascular endothelial growth factor signaling, angiogenesis, and tumor growth following oral administration. Cancer Res. 2002;62(16): 4645-4655.

16. Carlomagno F, Vitagliano D, Guida T, et al. ZD6474, an orally available inhibitor of KDR tyrosine kinase activity, efficiently blocks oncogenic RET kinases. Cancer Res. 2002;62(24):7284-7290.

17. Broutin S, Dupuy C, Caillou B, et al, editors. In vitro and in vivo activity of vandetanib in a human medullary thyroid carcinoma model bearing a RETC634W activating mutation. Proceedings of the American Association for Cancer Research; 2009; Denver, CO.

18. Vitagliano D, De Falco V, Tamburrino A, et al. The tyrosine kinase inhibitor ZD6474 blocks proliferation of RET mutant medullary thyroid carcinoma cells. Endocr Relat Cancer. 2011;18(1):1-11.

19. McCarty MF, Wey J, Stoeltzing O, et al. ZD6474, a vascular endothelial growth factor receptor tyrosine kinase inhibitor with additional activity against epidermal growth factor receptor tyrosine kinase, inhibits orthotopic growth and angiogenesis of gastric cancer. Mol Cancer Ther. 2004;3(9):1041-1048

20. Conrad C, Ischenko I, Kohl G, et al. Antiangiogenic and antitumor activity of a novel vascular endothelial growth factor receptor-2 tyrosine kinase inhibitor ZD6474 in a metastatic human pancreatic tumor model. Anticancer Drugs. 2007;18(5):569-579.

21. Drevs J, Konerding MA, Wolloscheck T, et al. The VEGF receptor tyrosine kinase inhibitor, ZD6474, inhibits angiogenesis and affects microvascular architecture within an orthotopically implanted renal cell carcinoma. Angiogenesis. 2004;7(4):347-354.

22. Wu W, Onn A, Isobe T, et al. Targeted therapy of orthotopic human lung cancer by combined vascular endothelial growth factor and epidermal growth factor receptor signaling blockade. Mol Cancer Ther. 2007; $6(2): 471-483$.

23. Checkley D, Tessier JJ, Kendrew J, Waterton JC, Wedge SR. Use of dynamic contrast-enhanced MRI to evaluate acute treatment with ZD6474, a VEGF signalling inhibitor, in PC-3 prostate tumours. Br J Cancer. 2003;89(10):1889-1895.

24. Bradley DP, Tessier JT, Checkley DR, Kuribayashi H, Wedge SR. The VEGF signaling inhibitors ZD6474 and AZD2171 compromise hemodynamic parameters in an SW620 human colon tumor model: An analysis using perfusion-permeability dynamic contrast-enhanced magnetic resonance imaging (pp-DCE-MRI). AACR Meeting Abstracts. 2004;2004(1):4552. 
25. Walter MA, Benz MR, Hildebrandt IJ, et al. Metabolic imaging allows early prediction of response to vandetanib. J Nucl Med. 2011; 52(2):231-240.

26. Verbeek HH, Alves MM, de Groot JW, et al. The effects of four different tyrosine kinase inhibitors on medullary and papillary thyroid cancer cells. J Clin Endocrinol Metab. 2011;96(6):E991-E995.

27. Holden SN, Eckhardt SG, Basser R, et al. Clinical evaluation of ZD6474, an orally active inhibitor of VEGF and EGF receptor signaling, in patients with solid, malignant tumors. Ann Oncol. 2005;16(8): 1391-1397.

28. Therasse P. Measuring the clinical response. What does it mean? Eur J Cancer. 2002;38(14):1817-1823.

29. Tamura T, Minami H, Yamada Y, et al. A phase I dose-escalation study of ZD6474 in Japanese patients with solid, malignant tumors. JThorac Oncol. 2006;1(9):1002-1009.

30. Zhang L, Li S, Zhang Y, et al. Pharmacokinetics and tolerability of vandetanib in Chinese patients with solid, malignant tumors: an open-label, phase I, rising multiple-dose study. Clin Ther. 2011;33(3): 315-327.

31. Wells SA Jr, Gosnell JE, Gagel RF, et al. Vandetanib for the treatment of patients with locally advanced or metastatic hereditary medullary thyroid cancer. J Clin Oncol. 2010;28(5):767-772.

32. Therasse P, Arbuck SG, Eisenhauer EA, et al. New guidelines to evaluate the response to treatment in solid tumors. European Organization for Research and Treatment of Cancer, National Cancer Institute of the United States, National Cancer Institute of Canada. J Natl Cancer Inst. 2000;92(3):205-216.

33. Robinson BG, Paz-Ares L, Krebs A, Vasselli J, Haddad R. Vandetanib $(100 \mathrm{mg})$ in patients with locally advanced or metastatic hereditary medullary thyroid cancer. J Clin Endocrinol Metab. 2010;95(6): 2664-2671.
34. Wells SA Jr, Robinson BG, Gagel RF, et al. Vandetanib in patients with locally advanced or metastatic medullary thyroid cancer: a randomized, double-blind phase III trial. J Clin Oncol. 2012;30(2):134-141.

35. Cabanillas ME, Hu MI, Durand JB, Busaidy NL. Challenges associated with tyrosine kinase inhibitor therapy for metastatic thyroid cancer. J Thyroid Res. 2011;2011:985780.

36. Duplomb S, Benoit A, Mechtouff-Cimarelli L, et al. Unusual adverse event with vandetanib in metastatic medullary thyroid cancer. $J$ Clin Oncol. 2012;30(2):e21-e23.

37. Yeh S, Fine HA, Smith JA. Corneal verticillata after dual anti-epidermal growth factor receptor and anti-vascular endothelial growth factor receptor 2 therapy (vandetanib) for anaplastic astrocytoma. Cornea. 2009;28(6):699-702.

38. Brassard M, Neraud B, Trabado S, et al. Endocrine effects of the tyrosine kinase inhibitor vandetanib in patients treated for thyroid cancer. J Clin Endocrinol Metab. 2011;96(9):2741-2749.

39. Abdulrahman RM, Verloop H, Hoftijzer H, et al. Sorafenib-induced hypothyroidism is associated with increased type 3 deiodination. J Clin Endocrinol Metab. 2010;95(8):3758-3762.

40. AstraZeneca. Vandetanib (ZD6474) tablets. Oncologic Drugs Advisory Committee (ODAC) Meeting Briefing Document. December 2, 2010. Available from: http:/www.fda.gov/downloads/AdvisoryCommittees/ CommitteesMeetingMaterials/Drugs/OncologicDrugsAdvisory Committee/UCM235092.pdf. Accessed on December 30, 2011.

41. Deshpande H, Roman S, Thumar J, Sosa JA. Vandetanib (ZD6474) in the treatment of medullary thyroid cancer. Clin Med Insights Oncol. 2011;5:213-221.
Biologics: Targets \& Therapy

\section{Publish your work in this journal}

Biologics: Targets \& Therapy is an international, peer-reviewed journal focusing on the patho-physiological rationale for and clinical application of Biologic agents in the management of autoimmune diseases, cancers or other pathologies where a molecular target can be identified. This journal is indexed on PubMed Central, CAS, EMBase, Scopus

\section{Dovepress}

and the Elsevier Bibliographic databases. The manuscript management system is completely online and includes a very quick and fair peerreview system, which is all easy to use. Visit http://www.dovepress com/testimonials.php to read real quotes from published authors. 